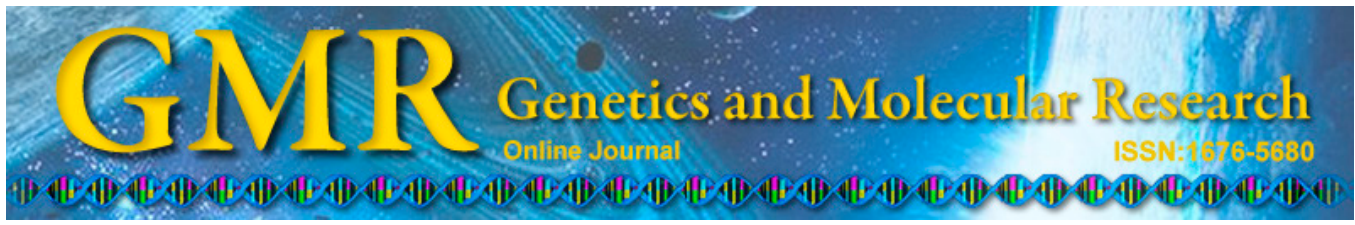

Short Communication

\title{
Isolation and characterization of microsatellite markers of sea cucumber Stichopus horrens
}

\author{
Z.B. Li ${ }^{1,2}$, G. Dai ${ }^{1,2}$, J.B. Shangguan ${ }^{1,2}$, Y.F. Ning ${ }^{1,2}$, Y.Y. Li ${ }^{1,2}$, \\ R.B. Chen ${ }^{1,2}$, Y. Yuan ${ }^{1,2}$ and Y.S. Huang ${ }^{1,2}$ \\ ${ }^{1}$ Fisheries College, Jimei University, Xiamen, China \\ ${ }^{2}$ Fujian Provincial Key Laboratory of Marine Fishery \\ Resources and Eco-Environment, Xiamen, China \\ Corresponding author: Z.B. Li \\ E-mail: lizhongbao@jmu.edu.cn
}

Genet. Mol. Res. 14 (3): 8496-8499 (2015)

Received December 10, 2014

Accepted April 28, 2015

Published July 28, 2015

DOI http://dx.doi.org/10.4238/2015.July.28.18

\begin{abstract}
Curry fish (Stichopus horrens) is a tropical holothurian species and is widely distributed in the India-West Pacific. In the present study, 9 polymorphic microsatellite loci were isolated and characterized for $S$. horrens. These loci were tested in 30 individuals from Hainan Island in China. The number of alleles ranged from 2 to 5 . The polymorphism information content ranged from $0.348-0.584$. The levels of observed and expected heterozygosities varied from 0.1500 0.8000 and from $0.2014-0.5000$, respectively. Most loci were in HardyWeinberg equilibrium, except HCS1-27 and HCS2-7, after sequential Bonferroni's correction, and no significant linkage disequilibrium was detected for any pairwise combination of loci. These polymorphic microsatellite loci will be useful for studying population structure and conservation strategy design for $S$. horrens.
\end{abstract}

Key words: Conservation; Microsatellite; Sea cucumber; Stichopus horrens 


\section{INTRODUCTION}

Sea cucumbers, or their dried form beche-de-mer, are generally consumed in Asia, where they are regarded as traditional medicine and delicacies. Stichopus horrens, commonly known as the curry fish, is a tropical sea cucumber and is widely distributed in the IndiaWest Pacific (Rowe and Gates, 1995). However, the natural resources of S. horrens have decreased sharply because of over-exploitation, and the species was listed as 'vulnerable' on the IUCN Red List (Hilton-Taylor and Mittermeier, 2000). Microsatellites, also known as simple sequence repeats or short tandem repeats, are powerful co-dominant genetic and molecular markers that have been used for various purposes, including stock management in fisheries (You et al., 2008). No microsatellite sequences were available in GenBank for S. horrens. In this study, we developed 9 polymorphic microsatellite loci in S. horrens for the genetic analysis and conservation of this species.

\section{MATERIAL AND METHODS}

The 9 polymorphic microsatellite loci were developed following fast isolation by amplified fragment length polymorphism of sequences containing repeats (Zane et al., 2002). Genetic DNA was extracted from the tube-foot tissues using a Genomic DNA Extraction kit (Tiangen Biotech Co., Ltd., Beijing, China). The DNA was digested using the restriction enzyme $\mathrm{Mse}$ (Fermentas, Vilnius, Lithuania) for $3.5 \mathrm{~h}$ at $65^{\circ} \mathrm{C}$, and the digested fragments were ligated to $M s e \mathrm{I}$ adaptor A (5'-GACGATGAGTCCTGAG-3')/MseI adaptor B (5'-TACTCAGGACTCAT-3') using T4 DNA ligase (Fermentas) overnight at $22^{\circ} \mathrm{C}$. The ligated fragments were hybridized to the biotinylated probes $(\mathrm{CT})_{15}$ and $(\mathrm{GT})_{15}$ as reported by Cao et al. (2013), and then captured by streptavidin-coated magnetic sphere particles (Promega, Madison, WI, USA). The recovered DNA fragments were amplified using the MseI primer (5'-GACGATGAGTCCTGAG-3') and purified using the GenClean Cycle Pure Kit (Omega bio-tek, Norcross, GA, USA) to remove the extra adaptors and dNTPs. The purified products were ligated into the pMD19-T vector (Takara, Shiga, Japan) and transformed into Escherichia coli competent cells DH5 $\alpha$ (Tiangen). The transformants were selected on LB agar plates containing ampicillin. Recombinant clones were amplified using universal M13 primers and the polymerase chain reaction (PCR) products were visualized by $1 \%$ agarose gel electrophoresis. A total of 242 positive clones ranging in size from 500-1000 base pairs were selected for sequencing by the Majorbio Company (Shanghai, China), and 63 pairs of primers were designed using Primer Premier 5.0 (Premier Biosoft, Palo Alto, CA, USA).

All 63 primer pairs were validated in 30 individuals of $S$. horrens collected from Hainan Island, China. PCR amplification was performed in a $10-\mu \mathrm{L}$ reaction volume containing 50 ng genomic DNA, $10 \mathrm{X} 2 \mathrm{mM} \mathrm{MgCl}$ Dream Taq buffer, 0.25 U Dream Taq DNA polymerase (Thermo Fisher, Waltham, MA, USA), $0.2 \mathrm{mM}$ dNTPs, and $0.4 \mu \mathrm{M}$ primers using a peqSTAR thermal cycler (PEQLAB, Erlanger, Germany). PCR was carried out under the following conditions: $95^{\circ} \mathrm{C}$ for $5 \mathrm{~min} ; 32$ cycles at $95^{\circ} \mathrm{C}$ for $40 \mathrm{~s}$, at Ta (Table 1) for 40 $\mathrm{s}, 72^{\circ} \mathrm{C}$ for $1 \mathrm{~min} ; 72^{\circ} \mathrm{C}$ for $10 \mathrm{~min}$; then stored at $4^{\circ} \mathrm{C}$. Amplified products were resolved by $6 \%$ denaturing polyacrylamide gel electrophoresis in a Sequi-Gen Sequencing Cell (Bio-Rad, Hercules, CA, USA). 
Table 1. Nine polymorphic microsatellite loci for Stichopus horrens.

\begin{tabular}{|c|c|c|c|c|c|c|c|c|c|}
\hline Locus ID & GenBank & Primer sequence $\left(5^{\prime}-3^{\prime}\right)$ & Repeat motif & $\mathrm{Ta}\left({ }^{\circ} \mathrm{C}\right)$ & Allele size (bp) & $N_{\mathrm{A}}$ & PIC & $H_{\mathrm{O}}$ & $H_{\mathrm{E}}$ \\
\hline HCS1-27 & KJ875908 & $\begin{array}{l}\text { F: TCGTGACACAAGTTCGGTT } \\
\text { R: CATGGTGGATGCCAATATC }\end{array}$ & $(\mathrm{AC})_{5}$ & 53 & $202-206$ & 2 & 0.432 & 0.0455 & $2014 *$ \\
\hline HCS2 & KJ875 & $\begin{array}{l}\text { F: GGAAATAAGGCGGGAACAC } \\
\text { R: CATACAACCACAGCCAACG }\end{array}$ & $(\mathrm{GT})_{24}$ & 45 & 19 & 3 & 0.584 & 0.8000 & $4800^{*}$ \\
\hline HCS3-15 & KJ875 & $\begin{array}{l}\text { F: GGATTACGCTGCTCTTTGAA } \\
\text { R: TGACCTGATAAACCCCACC }\end{array}$ & $(\mathrm{TG})_{43}$ & 45 & 1 & 3 & 0.496 & 0.5600 & 4032 \\
\hline HCS3-59 & KJ875911 & $\begin{array}{l}\text { F: TTGAAGAGGGCAGGTGAAC } \\
\text { R:AGCAGAGTAAAGAGGAGGAGCT }\end{array}$ & $(\mathrm{AC})_{12}$ & 53 & $1 \varepsilon$ & 2 & 0.523 & 0.1500 & .3487 \\
\hline HCS4-4-1 & KJ875912 & $\begin{array}{l}\text { F: AGAAACCGCACCTGACACTC } \\
\text { R: CAGACGGGAACATCACCATC }\end{array}$ & $(\mathrm{CTTGTC})_{3}$ & 49 & 104-110 & 3 & 0.433 & 0.5185 & 0.3841 \\
\hline HCS4-21-2 & KJ875913 & $\begin{array}{l}\text { F: CAGACGGGAACATCACCATC } \\
\text { R: CAGAAACCGCACCTGACACT }\end{array}$ & $(\mathrm{GACAAG})_{3}$ & 45 & 194-204 & 3 & 0.394 & 0.2400 & 0.2184 \\
\hline HCS4-22 & KJ875914 & $\begin{array}{l}\text { F: GACTCTACAAAAGGTCAGCCA } \\
\text { R: TGATACACAACAGGAACTCAGG }\end{array}$ & (A & 42 & $100-112$ & 5 & 0.348 & 0.4667 & 0.3828 \\
\hline $\mathrm{HC} 4$ & KJ $8^{-}$ & $\begin{array}{l}\text { F: GTAATACTCATCGGCACTCCA } \\
\text { R: TCCATCAAAACCAACCCTC }\end{array}$ & $(\mathrm{AG})_{21} \mathrm{~N}(\mathrm{GT})_{34}$ & 45 & 188-192 & 4 & 0.486 & 0.4400 & 0.3848 \\
\hline HCS4-78 & KJ875916 & $\begin{array}{l}\text { F: GGTTTGTTATTGACGCCCAC } \\
\text { R: GCTTGTTTGAAGCCTCCACT }\end{array}$ & $(\mathrm{AG})_{55}$ & 45 & $136-140$ & 3 & 0.568 & 0.7500 & 0.5000 \\
\hline
\end{tabular}

Annealing temperature (Ta), allele size, the polymorphism information content (PIC), the number of alleles per locus $\left(N_{\mathrm{A}}\right)$, observed heterozygosities $\left(H_{\mathrm{O}}\right)$, expected heterozygosities $\left(H_{\mathrm{E}}\right)$ * * Significant deviations of locus from Hardy-Weinberg equilibrium after Bonferroni’s correction.

\section{RESULTS AND DISCUSSION}

We successfully amplified 9 polymorphic loci as shown in Table 1 . The number of alleles per locus, polymorphic information content, and observed and expected heterozygosity values were calculated using the POPGEN32 version 1.32 (Yeh et al., 2000) and CERVUS 3.0 version 2.2.3 software (Kalinowski et al., 2007). Deviations from Hardy-Weinberg equilibrium and evaluated genotypic linkage disequilibrium were tested using POPGENE 32 version 1.32.

The number of alleles ranged from 2-5. The polymorphism information content ranged from $0.348-0.584$. The levels of observed and expected heterozygosities varied from $0.1500-0.8000$ and from $0.2014-0.5000$, respectively. No significant linkage disequilibrium was detected for any pairwise combination of loci. Most loci were at Hardy-Weinberg equilibrium $(\mathrm{P}>0.05)$, except HCS1-27 and HCS2-7, even after sequential Bonferroni's correction $(\mathrm{P}<0.00556)$, which may be attributed to the limited number of samples tested.

The novel microsatellite loci identified in this study will be useful for studying genetic diversity, population structure, and conservation strategy design for S. horrens.

\section{Conflicts of interest}

The authors declare no conflict of interest.

\section{AKNOWLEDGMENTS}

Research supported by the National Natural Science Foundation of China (\#31272668), the Returned Scholars Project of the Ministry of Education of China [\#(2006)331], the Foundation for Innovative Research Team of Jimei University, China (\#2010A004), and the Program for New Century Excellent Talents in Fujian Province University [\#(2006)35]. 


\section{REFERENCES}

Cao YY, Li ZB, Li QH, Chen XJ, et al. (2013). Characterization of eight novel microsatellite markers in the green-lipped mussel Perna viridis (Mytilidae). Genet. Mol. Res. 12: 344-347.

Hilton-Taylor C and Mittermeier RA (2000). IUCN red list of threatened species. IUCN, Gland.

Kalinowski ST, Taper ML and Marshall TC (2007). Revising how the computer program CERVUS accommodates genotyping error increases success in paternity assignment. Mol. Ecol. 16: 1099-1106.

Rowe FWE and Gates J (1995). Echinodermata. In: Zoological Catalogue of Australia. Vol. 33 (Wells A, ed.). CSIRO, Melbourne.

Yeh FC, Yang R, Boyle TJ, Ye Z, et al. (2000). PopGene32, Microsoft Windows-Based freeware for Population Genetic analysis. Version 1.32. Molecular Biology and Biotechnology Centre. University of Alberta, Alberta.

You FM, Huo N, Gu YQ, Luo MC, et al. (2008). BatchPrimer3: a high throughput web application for PCR and sequencing primer design. BMC Bioinformatics 9: 253.

Zane L, Bargelloni L and Patarnello T (2002). Strategies for microsatellite isolation: a review. Mol. Ecol. 11: 1-16. 